\title{
Traveling Fellow en USA 2009
}

\author{
M. Llusá PÉRez
}

Miembro de la SECMA. EsPeCIALISTA EN CIRUGía ORTOPÉdica Y TRAUMATOLOGÍA

Diploma de la FESSH de CiRUGía de LA MaNo

MÉdico Especialista, Unidad de Microcirugía y NeURo-ortopédia. SERVICIO COyT.

Hospital de la Vall d'Hebrón. Barcelona

Correspondencia:

Dr. Manuel LLusá Pérez

Hospital de la Vall d'Hebrón

Dirección Hospital Paseo Vall d'Hebrón, 119-129

08035 Barcelona

Teléfono: +34934893481

e-mail: mllusa@ub.edu

$\mathrm{T}$ enía la intención de asistir al congreso de la AASH del año 2009 antes de publicarse esta convocatoria conjunta de la SECMA y de la ASSH, habiendo presentado un trabajo en forma de DVD al Congreso de San Francisco. Asimismo, estaba interesado en visitar varios Centros de Estados Unidos, por lo que había contactado con varios especialistas para poder aprender y actualizar conocimientos en áreas específicas, concretamente en microcirugía, cirugía de los nervios periféricos y aloinjertos. Los especialistas y Centros con mayor interés eran en principio:

Dr. Vincent R Hentz, Cirujano Plástico del Hospital de Stanford, California, especialista con gran experiencia en Cirugía de la Mano del paciente tetrapléjico y cirugía reconstructiva, incluyendo nervios periféricos y plexo braquial. Contacté personalmente con él en varias reuniones en Europa sobre tratamiento de las lesiones de los nervios periféricos y mano tetrapléjica.

Dr. Milan Stevanovic, Cirujano Ortopédico del Keck School of Medicine of USC, California. Me interesaba por su amplia experiencia en las indicaciones y técnica de los injertos de músculos libres funcionales microquirúrgicos, especialmente gracilis, y sus ideas sobre la reconstrucción de las secuelas de lesiones del plexo braquial y síndromes compartimentales. Contacte con él en el congreso de la FESSH celebrado en Atenas 2007.
Visitar la Division of Plastic and Reconstructive Surgery de la Universidad de Duke, dirigida por el Dr Scott Levin con gran experiencia en procedimientos microquirúrgicos de la mano y extremidad superior. También era mi intención aprovechar la oportunidad de ver sus instalaciones del Duke Human Fresh Tissue Lab y conocer como organizan los cursos de formación, incluyendo aspectos éticos en relación con el uso de las donaciones de cuerpos.

Finalmente, tenía intención de asistir al Instituto Kleinert de microcirugía, en Louisville, Kentucky, para contactar con el equipo de cirujanos y especialistas relacionados con el tema de trasplante de mano del que son pioneros. En el año 2002 tuve la ocasión de estar un corto periodo de tiempo con el Dr. Luis Scheker, el Dr. Warren G. Breidenbach y el Dr. Rubén González quien realizaba trabajos de laboratorio experimental en relación con los problemas de los aloinjertos.

Casualmente ese año había solicitado una estancia en la Clínica Mayo, y precisamente el mes de septiembre era un periodo de tiempo en que no tenía ninguna actividad planeada, pues en principio mi idea era acudir al Congreso de la ASSH si me aceptaban la presentación del DVD de anatomía quirúrgica y vías de abordaje de los nervios periféricos. Al publicarse esta convocatoria, el hecho de tener preparado el curriculum traducido al inglés y los contactos previos con 
los diferentes especialista facilitaron la decisión de solicitar este beca; así que, primer consejo: vale la pena tener actualizado el curriculum y traducido al inglés para poder optar a las cada vez más frecuentes opciones de visitar un centro extranjero, fellowships, estancias, etc., así como conocer quiénes son las personas y centros con los que debemos contactar.

Fue una grata sorpresa recibir la confirmación de que había sido seleccionado para acudir al Congreso de la ASSH en San Francisco y la ayuda, no solo económica sino el respaldo institucional de la SECMA, para visitar los centros elegidos. Desde el primer momento tuve el apoyo y consejos de diferentes personas de la junta y también de las personas de enlace con la AASH, muy especialmente de Mrs. Tara Havenga y Alexandra Wallacey de los doctores Ángel Ferreres, Gabriel Celester, Miguel Cuadros, Enrique Mackenney, José María Arandes, etc. Ello fue esencial pues era la primera vez que se concedía este tipo de ayuda entre la ASSH y la SECMA. Ir respaldado con el nombre institucional abrió las puertas de forma automática, eliminándose muchos de los tediosos requisitos exigidos por los distintos hospitales y administración de Estados Unidos al estar también bajo el amparo de la AASH. Con todo ello, hay que disponer con anticipación de un programa de visita e intentar que sea en lugares cercanos al punto geográfico donde se realiza el Congreso, y éste es el segundo consejo: Estados Unidos es un país con unas distancias enormes y trasladarse dentro de él consume tiempo y dinero. La organización de los vuelos y hoteles te la debes organizar tu mismo de acuerdo a tu programa de visitas. Solo comentar que los vuelos no siempre son tan baratos, y si lo son hay que hacer varias escalas, perdiéndose tiempo y energía. Y los hoteles no siempre están cerca de los hospitales que deseas visitar. Muchos de los hoteles no están tan bien comunicados como aquí en España, y recordar que en Estados Unidos casi todo el mundo se mueve en su propio coche o hay que usar taxis no tan baratos como en nuestro país.

A continuación os narrare mi experiencia personal que fue totalmente positiva.

Asistí al congreso de la ASSH en San Francisco. Como muchos de los Congresos americanos, se trata de un macroevento que llega a aturdir.

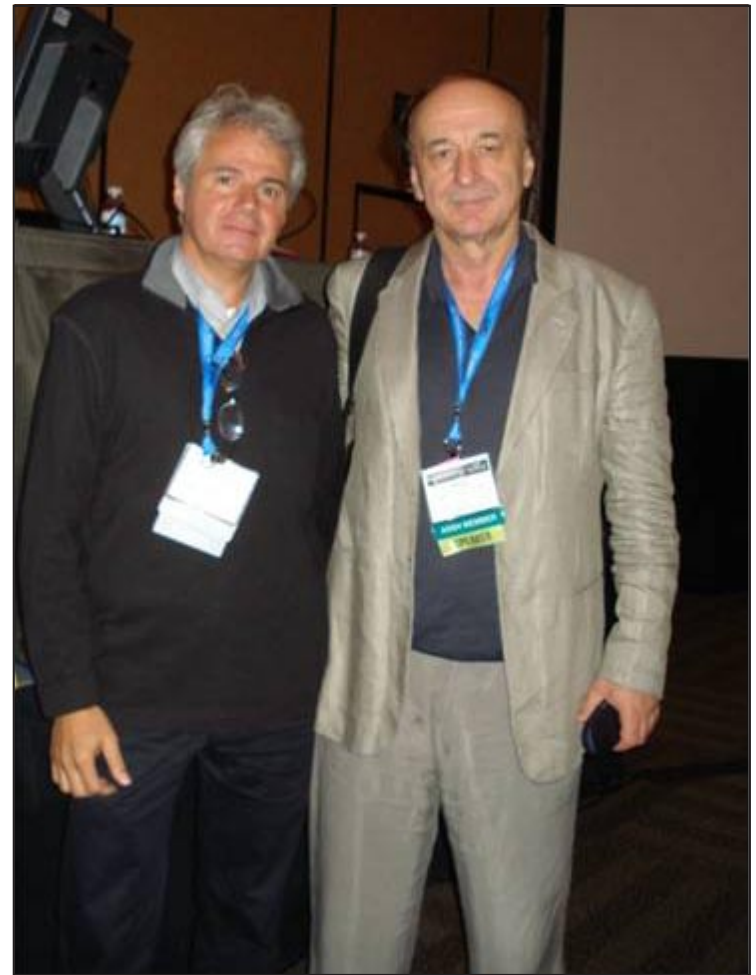

Figura 1. Congreso de la ASSH en San Francisco 2009, junto al Dr. Milan Stevanovic.

Tercer consejo: llevar bien estudiado y preparado el programa de comunicaciones y mesas a las que queréis asistir; de esta forma se puede llegar a sacar el máximo provecho a la amplísima oferta científica. Los cursos de instrucción se pagan aparte y no están incluidos en la inscripción, pero realmente si se selecciona bien del programa veréis que casi no tendréis tiempo material para todo. En el Congreso tuve la oportunidad de comentar y debatir ampliamente con el Dr. Milan Stevanovic acerca de las indicaciones y resultados de las trasposiciones musculares funcionales (Figura 1), especialmente del músculo gracilis, y también con el Dr. Christopher Oberlin sobre diferentes opciones de tratamiento en las lesiones complejas del plexo braquial; sus comentarios y punto de vista me aclararon algunas dudas que no encuentras en los libros o revistas. A nivel personal me alegró ver que en una de las ponencias de lesiones de los tendones flexores se estaban utilizando imágenes del libro de Anatomía publicado por nosotros

A continuación me trasladé a Palo Alto para visitar al Dr. Vincent R. Hentz, una autoridad científica en el campo de la cirugía reconstruc- 


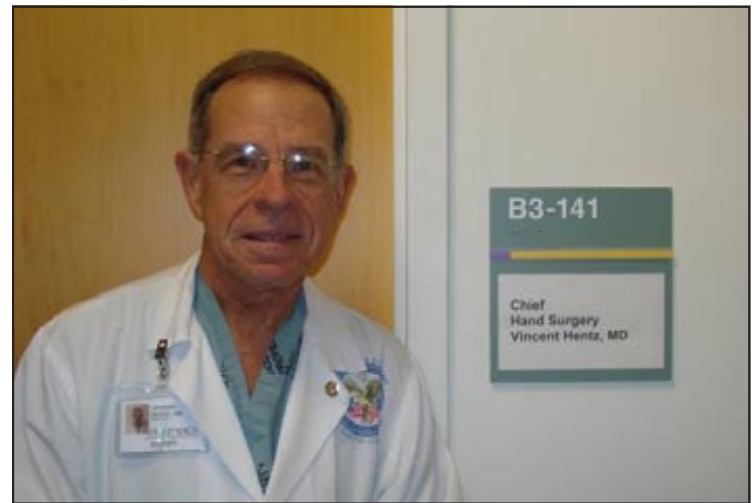

Figura 2. Dr. Vincent R. Hentz en su oficina del Hospital de Veteranos. Palo Alto, California.

tiva funcional de la extremidad superior de los pacientes tetrapléjicos. Pude asistir al Hospital de Veteranos del Ejército Americano donde visitamos varios de sus múltiples departamentos, destacando la Unidad de Lesiones Medulares, área de rehabilitación y centro de investigación neuroortopédico (Figura 2). Además, de la mano del Dr. Hentz pudimos conocer al resto del equipo de Cirugía Plástica de la Universidad de Stanfort: la Dra. Amy Ladd, Dr. James Chang, Dra. Emily Chung entre otros. Lo que más me impresionó es el cuidado y mimo con el que realizan todas las actividades...eso sí, disponiendo de tiempo y medios suficientes, dictáfonos para casi todo o programas de reconocimiento de voz en ordenador, secretarias, Phyisician assistants (una figura entre enfermera especializada, técnico y residente, que descarga una enormidad el trabajo no estrictamente médico como explicar el preoperatorio, burocracia, coordinación de visitas y exploraciones, etc...).

Como colofón la gran sorpresa fue conocer al Dr. Robert Chase, autentico pilar del desarrollo de la Cirugía de la Mano en Estados Unidos y además un excelente anatomista, que aún está en activo, desarrollando programas de educación para Cirujanos de la Mano, especialmente en relación con anatomía quirúrgica (Figura 3). $\mathrm{Su}$ ejemplo será algo a recordar el resto de mi vida; con 87 años es tan vitalista y entusiasta que sorprende, ¡su salud es también admirable!. Su obra Atlas of Hand Surgery (1973) es una Biblia en Cirugía de la Mano

Posteriormente visité a la Dra. Susan Mckinnon, quien trabaja en el Hospital de Sant Louis,

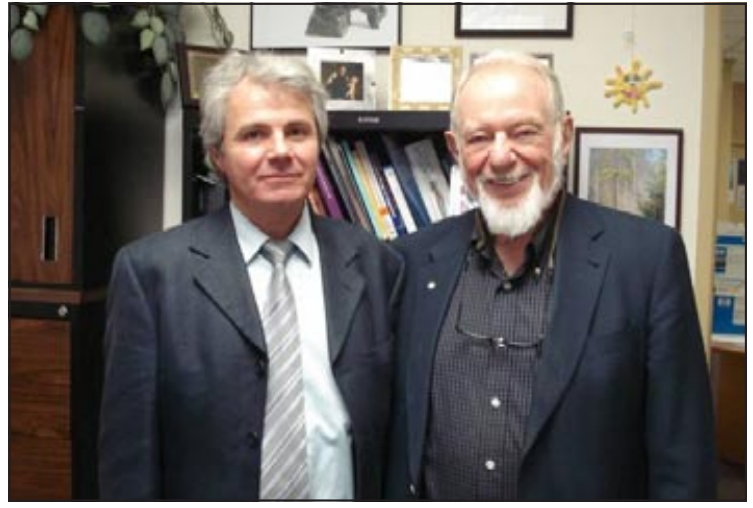

Figura 3. Estancia en la Universidad de Stanford, junto al Dr. Robert Chase.

Missouri. Ella se define como cirujana de nervios periféricos, y si se revisan sus publicaciones así es, y además sus ideas de las trasposiciones nerviosas son muy novedosas e inteligentes (Figura 4). Su experiencia clínica es abrumadora sorprendiendo la cantidad de recursos y trucos clínicos y quirúrgicos que emplea, sin duda fruto de las horas de contacto con las patologías que trata. Especialmente me sorprendió su «Scratch test» publicado en el J Hand Surg Am, 2008; 33: 1518-24. Tardé tiempo en entender lo que significa. La eficacia en su práctica hospitalaria es tal que los pacientes procedentes de diferentes estados se visitan un día y pueden ser operados al día siguiente, realizando todas las exploraciones complementarias y preoperatorio en pocas horas...¿¿Disponibilidad de quirófano? ¡Siempre disponible!

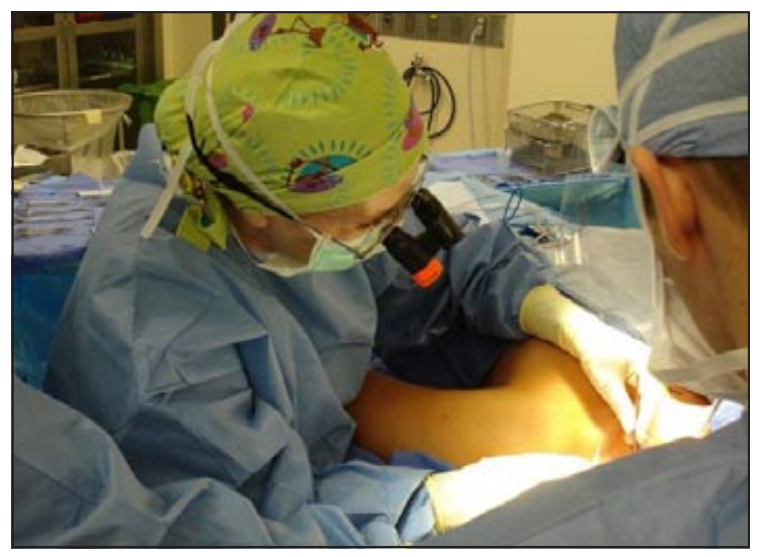

Figura 4. Un día de quirófano con la Dra. Susan Mackinnon en el Hospital de la Universidad de Washinton, Sant Louis, Missouri. 


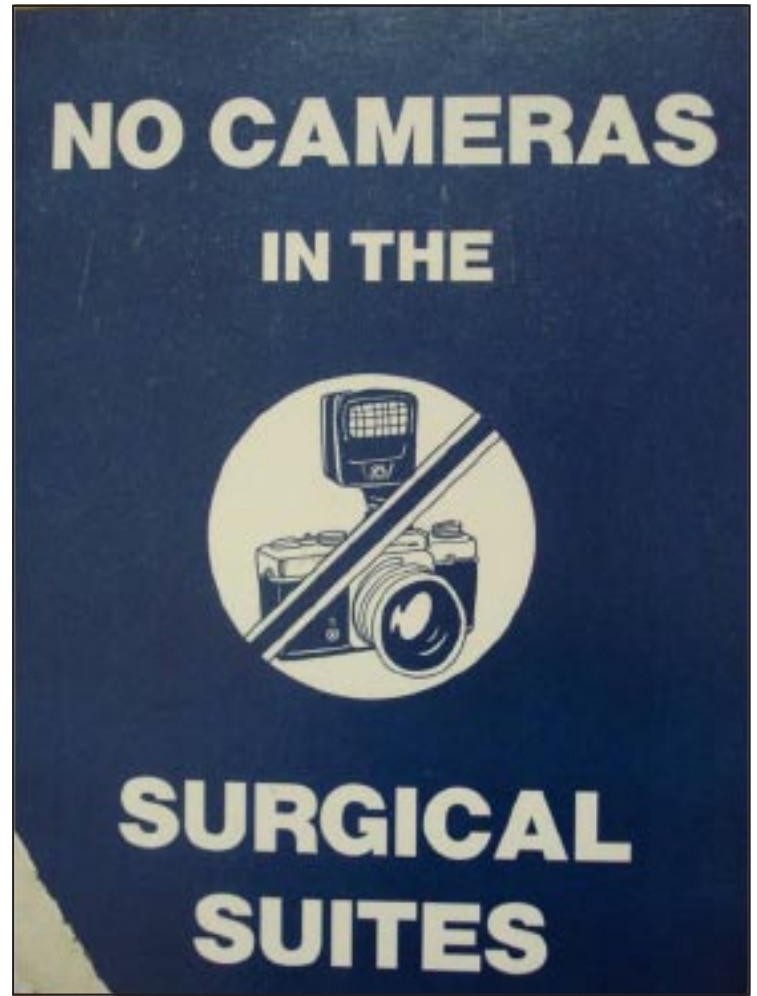

Figura 5. Acceso restringido de cámaras en la mayoría de Hospitales.

Finalmente debido a que el Dr. Scott Levin cambió de Universidad y Hospital, trasladándose a Pensilvania, estuve visitando a diferentes Cirujanos de Extremidad Superior de la Clínica Mayo, con los que había tenido contacto a través del Dr. Joaquín Sánchez Sotelo y Miguel Cabanela quienes me habían tutorizado mientras estuve en Rochester, Minnesota, y a los que agradezco toda su ayuda y apoyo. Solo la visita a la Clínica Mayo es ya una experiencia interesante de vivirla, pero si además te permiten ver de cerca cómo funcionan y el elevadísimo nivel, especialmente en investigación, docencia y trato médico a los pacientes (sus tres pilares de funcionamiento) es muy gratificante. La confidencialidad es importantísima no permitiéndose en ningún momento el uso de cámaras; si se precisa iconografía se llama o envía al paciente al departamento de fotografía (Figura 5). Pudimos asistir a una de las unidades especializadas de lesiones de los nervios periféricos y plexo braquial dirigidas por los doctores Allen Bishop y Alex Shin, con un equipo multidisciplinar de

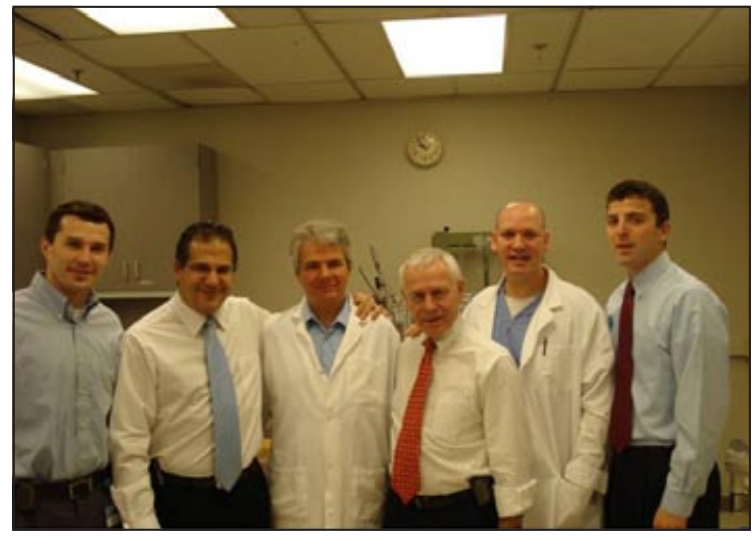

Figura 6. En el Laboratorio de Biomecánica de la Clínica Mayo, junto al Dr. Bernard F. Morrey, Joaquín Sánchez. Sotelo y su equipo.

envidia; lo que no puedan solventar ellos es que realmente es casi imposible de arreglar. Visitan una vez cada 15 días pero con una gran intensidad y un número de pacientes que rondan los 100. Comienzan a las 8 de la mañana y terminan alrededor de las 5 ó 6 de la tarde sin parar; las calorías se ingieren al más típico estilo de trabajo norteamericano, y !nada de descansitos!. En esa misma consulta visita el Dr. Bassem El Hasam, joven médico de origen libanés, listo y habilidoso cirujano; sus ideas sobre las trasposiciones tendinomusculares alrededor del hombro están modificando el tratamiento de las lesiones del plexo braquial, especialmente en el niño. Su idea es preservar al máximo el nervio espinal para poder realizar trasposiciones musculares con las diferentes porciones de trapecio para reanimar la abducción y rotación externa del hombro. Podéis buscar sus trabajos en la bibliografía. El contacto con el Dr. Richard A. Berger fue asimismo muy enriquecedor. Cirujano con ideas muy claras de la anatomía funcional, y amplia experiencia en la articulación radiocubital distal, su hobbytrabajo. Finalmente agradecer especialmente al Dr. Joaquín Sánchez Sotelo, Bernard F. Morrey, Scott Steimann y a nuestro «cónsul medico» en Rochester, el Dr. Miguel Cabanela, por su gran acogida y facilitarnos nuestra estancia en tierras tan lejanas y frías. Un poco de calor compatriota ayuda bastante... así que también gracias a Antonio Foruria, Loles, y todos los hispanos-latinos con los que compartimos «lunchs» $\mathrm{y}$ «diners» $\mathrm{y}$ algo de tiempo libre. 


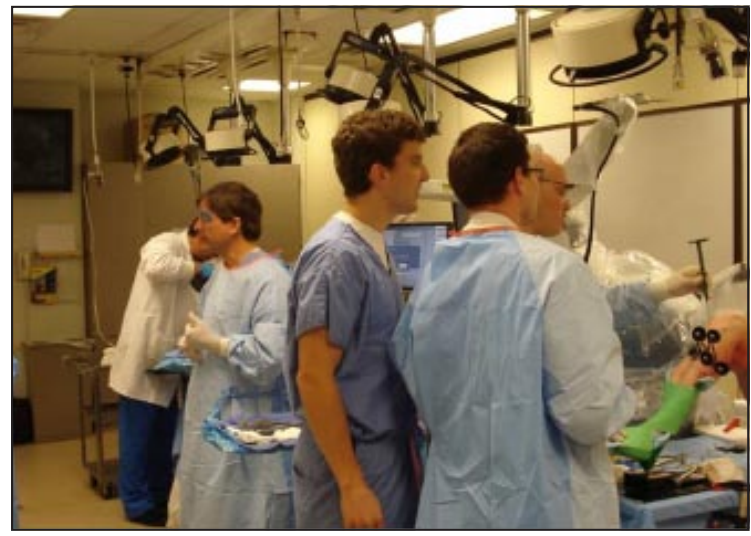

Figura 7. Laboratorio del Departamento de Anatomía. Curso de prótesis de rodilla con navegador y asistencia de robot.

En Rochester también pudimos visitar el Departamento de Biomecánica, dirigido por el Profesor Kai-Nan An, junto con el Dr. Bernard F. Morrey (Figura 6), y el Departamento de Anatomía Humana de la Mayo Medical School, dirigido por el Dr. Pawlina Wojciech y Nirusha Lachman con quienes pudimos dialogar sobre los aspectos éticos de la donación de cuerpos y su utilización para la docencia e investigación (Figura 7). La Asociación de Anatomía Clínica Americana ha alertado que en Estados Unidos la presión comercial de la industria de los implantes ha desvirtuado este fin, empleándose cada vez más las donaciones, principalmente, o únicamente, para divulgar un tipo determinado de prótesis o material quirúrgico. Esto ha llegado a unos extremos de que se han creado compañías denominadas de «servicios anatómicos» que compran y venden los cuerpos, con múltiples variedades de transacciones... incluyendo la exportación al extranjero. De hecho, en España hace unos años que se comenzó a importar segmentos corporales congelados para la realización de estos cursos y estamos en una situación parecida pero sin una legislación ni organización clara.
Para terminar sólo comentar que a la hora de tomar las decisiones es importante no sólo valorar qué ver y a quién visitar, si no también donde se localiza el Hospital o Universidad y las opciones de traslado y alojamiento; para ello, son esenciales la persona de contacto de la AAHS y de cada centro en particular, pues son quienes mejor nos pueden aconsejar y acertar en nuestras decisiones

¿Para qué me ha servido todo esto? Ante todo, y aunque las comparaciones son odiosas, para verificar que tampoco lo hacemos tan mal aquí. Muchos de los procedimientos y técnicas las realizamos de forma similar pero quizás con menos medios, y sobre todo con menos organización hospitalaria. Segundo, aprender de primera mano técnicas que has leído en libros o revistas efectuadas por sus autores originales, pudiendo filtrar aún más sus conocimientos. Tercero, y no menos importante, contactar con personas que nos han brindado la posibilidad de seguir en relación, como ha sido el caso del Dr. Vincent R. Hentz que acudió a Barcelona para participar en la reunión del grupo «Wings for life», organización de apoyo al estudio de las lesiones medulares, organizado por el Dr. Xavier Mir junto con el RACC, o la invitación que nos hizo la Dra. Amy Ladd para participar en comunicaciones y mesas redondas en el Congreso Mundial de Cirugía de la Mano realizado en Seúl en noviembre del 2010, y sobretodo abrir nuestra mente y pensar en diferentes soluciones y nuevas opciones ante los problemas cotidianos que vemos en nuestra consulta de Cirugía de la Mano, microcirugía y especialmente neuroortopédia, incluyendo las lesiones del plexo braquial, nervios periféricos, trasposiciones tendinosas de la extremidad superior en el tetrapléjico, etc.

Gracias a la AAHS y la SECMA por ofrecernos esta interesante oportunidad que seguro es bien acogida y valorada por los socios de la SECMA. 